\title{
Caregiver's Sensitivity and Attachment Security in Early Childhood Education Settings in the Kpandai District of the Republic of Ghana
}

\author{
Issah Aduna \\ Department of Education and Professional Studies, Bagabaga College of Education, PO box 35 E/R, Tamale, \\ Northern Region-Ghana
}

\begin{abstract}
Caregiver sensitivity in early childhood education settings is considered as a significant association moderating between the caregivers and children's learning outcome. The current study advance the very limited knowledge about Ghanaian early childhood education settings particularly in Kpandai District and use a wide range of prior literature based on sensitivity hypothesis of attachment theory that relates sensitive nurture with attachment security. The study is quantitative in nature design to analyze the relation between 16 caregivers' sensitivity and attachment security of their preschool children. Two instruments were used for assessment: Caregiver Behaviour for Pre-schoolers Q-set and Attachment Behaviour Q-set Version 3.0. The study posits a level of sensitivity similar to the previously reported, and a slightly higher level of children security was found. Regarding the relation between both variables, sensitivity was found as a predictor of attachment security. The study, however, recommended a replication of this study in other cultural contexts in which the paternal figure be included and with other development conditions groups.
\end{abstract}

Keywords: caregiver sensitivity, attachment relations, early childhood education

DOI: $10.7176 /$ RHSS/10-17-05

Publication date:October $31^{\text {st }} 2020$

\section{Introduction}

Caregiver sensitivity refers to the ability of a caregiver to respond, to be emotionally available and provide contingent, appropriate and consistent response to a child's emotional and physical needs (Gerber et al, 2007). Positive interaction depends in large part on the capacity of caregivers to sensitively respond to the needs of young children. Additionally, caregiver sensitivity is the ability to recognize children's individual needs from the most basic to complex and to respond contingently with a positive approach that scaffolds development and learning. Caregiver sensitivity in positive caregiver-child relationship is important resource for early prevention and intervention in young children. It, therefore, suggest that when child care settings are of high quality and sensitive, children growing up in disadvantaged early childhood environment like in most parts of Ghana, may benefit from secure and positive relationships with their caregivers which contribute uniquely to their social and emotional development and school readiness

Dunst and Kassow (2004), states emotional sensitivity and responsive caregiving is a requirement for healthy neurophysiological, physical and psychological development of a child. Literature indicated that caregiver-child reciprocal and mutual reinforcing interactions in early childhood education setting situation are most likely to contribute to improved caregiver-child early childhood education setting relationship and this in turn will optimally influence child learning competence. Hamre (2014), postulate that early childhood education settings are pleasant places in which children are supported with positive relationships by caregivers and peers and caregivers are sensitive to children's individual needs thereby creating a positive classroom climate.

Positive classroom climates are, by their very nature, social places (Hamre \& Pianta, 2011). They are where caregivers and children laugh and play together, share stories about their lives in and outside the classroom, and work together to create an environment in which all learning occurs. One part of such positive classroom climate is emotional support which is the emotional connection between caregivers and children's and among children's, and the warmth, respect and enjoyment communicated by verbal and non-verbal interactions (Paro et al, 2009). Caregiver's sensitive and positive instructional interactions in early childhood education setting measures such as emotional support, classroom organization and instructional support are the domains that promote the wellness and enjoyable interactions. It is only by these multifaceted and holistically views of an early childhood education setting that can well support early development and learning (Hamre, 2014).

Also the quality of interactional sensitivity provides evidence that beyond cognitive functioning and classroom behaviour, children's ability to form relationships with their caregivers forecast later academic and behavioural adjustment in school (Oliveira et al, 2014)). This shows that even for children for whom generally positive school performance is predicted, the early childhood education setting caregivers-child relationship is an important indicator of early adaption and a marker of late behaviour outcomes but for disadvantaged children this is even more important. Finally it is important to state that the association between the quality of early caregiver- 
child relationships and later school performance can be both strong and persistent when caregivers are sensitive in early education settings. This association is apparent in both academic and social sphere of school performance.

\section{Early childhood education classroom setting and the attachment theory}

Ainsworth (1973) and Bowlby (1969) postulate attachment as a deep and enduring affectionate bond that connects one person to another across time and space (Bergin \& Bergin, 2009). They indicated that attachment has at least two functions pertinent to classroom. One is attachment provides feelings of security, so that children can explore freely, indicating that all children seek to feel secure (Bergin \& Bergin, 2009). Attachment helps them balance this need with their innate motivation to explore their environment. Secondly attachment forms the basis for socializing in children.

As children and caregivers are drawn together and interact harmoniously, children adopt the adults' behaviours and values. Also to be effective, caregivers must connect with and care for children with warmth, respect, and trust. It therefore means that, the first job of early childhood setting is to care for children. Hence, it will be morally and practically wrong to assert that early childhood settings should only concentrate on academic goals as the case of early childhood education settings in Ghana. Rather, early childhood education settings should conceptualize the provision of learning opportunities as interactions between caregivers and children with empirically supported links to children's emotional and social needs

Children do not learn academically if they are not cared for, hence caregivers' emotional availability is critical for the creation of secure heavens for children to explore. Even though emotional availability and sensitive caregiver-child relationships may seem like a low priority in a context of many childhood settings due to challenges and multi-risk factors to children's development in Ghana, research shows that, children's socioemotional well-being is linked to achievement (Bergin \& Bergin, 2009).

According to the literature, understanding of the relationship is important because attachment security during the early childhood education period is related to a wide range of outcomes, both adaptive and maladaptive and in later child development and learning. Empirical literature suggests that attachment is related to concurrent caregiver sensitivity. This is to say that, studies provide evidence to the fact that concurrent aspects of caregiving specifically a measure of sensitivity takes into account the caregiver's respect for the child's increasing need for warmth, responsive and sensitive care (Ritchie \& Howes, 2003), as well as sensitivity/scaffolding, support/engagement and hostility/coercion, are directly related to attachment security (Hopkins et al, 2013).

The attachment-like security in early education settings revealed that caregivers of securely attached children create a context of reciprocity based on positive affect and emotional understanding which fosters children's willingness to internalize rules of conduct in classroom settings (Dozier et al, 2001). It is therefore important for caregivers to recognize that sensitive interactional instructions provide a proximal condition for interactional play which is a good variable for learning and development outcomes.

Development of these variables in an early childhood setting programmes specifically serving children from difficult life circumstances in the case of Ghana are more likely to use relationship practice (Ritchie \& Howes, 2003, ). The ground work (Emotional support, Classroom organization, and Instructional support); the basic principle of positive caregiver practices will allow children to form important relationships with their caregivers so that they are ready to take the opportunities to learn that are variable to them in the programmes they attend. What it means is that children, who enjoy these domains in a setting, will develop positive child-caregiver relationships and will be able to make use of the learning opportunities available in classroom and better adjust to the demands of formal schooling.

Hamre and Pianta (2007) defined these learning opportunities as "interactions between adults and children with empirically supported links to children's social, emotional, and academic development" .Other learning opportunities include the amount of exposure children have to particular types of instructional interactions (e.g., literacy and language lessons, math instruction, etc) as well as the quality of those interactions.

These centre-based interactional instruction caregiving in early education has been identified as being caregiver sensitivity, warm and responsive to children and being able to motivate and manage children in the early childhood settings (Gerber et al, 2007). Confirmed here by Paro et al (2009) stated that the increased attention to interactions as a key indicator of classroom quality arises from strong and consistent evidence that these interactions are linked to children's academic, language, and social development.

Finally, higher quality early childhood setting (Emotional support, Classroom organization \& Instructional support) is the key to healthy relationships from early childhood education settings to high school. It is important to note that in early education settings, caregiver sensitivity in caregiver-child interaction is more predictive of academic, language, and social skill development than other aspects of the early education setting (Mashburn et al 2008). More importantly, promoting attachment-like caregiver-child relationships and school bonding should be prioritizing because it promotes children's learning. 


\section{Current Study}

In perspective, that's in relation with the research discussed above, this study was based on the sensitivity hypothesis of attachment theory, which relates sensitive childrearing with security (van IJzendoorn \& SagiSchwartz, 2008), through a quantitative research approach. The aim was to analyze the relation between sensitivity in a group of caregivers and the attachment security of their typically developing preschool children - all residents of Kpandai District - in order to generate contextual knowledge and to count with referential data that can serve as a base to work with other cultural groups and populations with different capacities.

\section{Materials and Methods}

\subsection{Participants}

The participants in this study were 16 dyads of caregivers and their typically developing early childhood-aged child, middle socio-economic status, residents of Kpandai District. As inclusion criteria for caregivers, the researcher established the requirements of their being adults and having, at least, completed Senior High School education.

To recruit the participants in this period of Covid-19, the information about the study was disseminated through social media especially Whatsapp groups using the google forms template. The persons who manifested their interest in participating and who also met the inclusion criteria were asked to sign an informed consent form in which the adults, as legal guardians, authorised the participation of their children. Additionally, through an initial interview, socio-demographic information was gathered, as well as data on child's development. Therefore, the selection of the participants was carried out by using convenience sampling. The process started out with 22 dyads, of which only 16 remained to the end.

In call cases, the caregivers were self-identified as principal caregivers of the children. Their ages fluctuated between 22 and 44 years $(M=33.81, S D=5.62)$. In relation to their educational level, the average for years of study was 15.63 (Min=12, Max=18, $\mathrm{SD}=.96$ ), thus, there among them (19\%) had completed Senior High School, 10 $(62 \%)$ had received undergraduate level higher education, and the remaining three $(19 \%)$ had received graduate level education. Concerning the number of children for each caregiver, eight among them (50\%) had only one child, three (18.75\%) had two children, and five (31;25\%), had three children.

The children were between 36 and 71 months of age $(M=56.94, S D=7.91)$; eight of them (50\%) were boys and eight $(50 \%)$ were girls. Concerning their ordinal positions, eight were only children $(50 \%)$, four were older siblings $(25 \%)$, two were middle children (12.5\%), and two were younger siblings $(12.5 \%)$. During the initial Interview with the caregivers, the researcher verified that all the children had undergone a bio-psycho-social development within the norm. When the process was over, as a benefit for participating, recommendations were offered to caregivers on ways to strengthen their attachment bond with their children.

\subsection{Measures}

4.2.1 Sensitive Caregiving. The sensitivity of the caregiving was assessed using the Caregiver Behaviour for Preschoolers Q-Set (MBPQS) scale. The researcher applied the updated version (Posada, Kaloustian, Richmond, \& Moreno, 2007), which was linguistically adapted to include Ghanaian idiomatic expressions especially as indigenous to the people of the Kpandai District. The MBPQS consists of 90 statements that describe behaviours related to the sensitivity construct, 55 of which refer to four dimensions: Contribution to harmonious interactions (CHI), Secure Base Support (SBS), Supervision and monitoring (SUP), and Limit Setting (LS).

According to Posada and collaborators (2007), during the administration of the scale two evaluators observe independently the behaviour of the caregiver in her interaction with the child, in their natural environment, and apply the items of the scale that are not easily observable (e.g., Item 67: "When setting rules and prohibiting an activity to child, explains reasons"), in an interview style manner. Afterwards, the assessors use the Q-sort methodology to assess the behaviour that was observed, and, to do so they classify the 90 statements into groups that range from 9 to 1 with 10 statements in each group, in such a way that in group 9 they classify the behaviours that are most characteristic of the person who is being assessed, and in group 1, the least characteristic. Then, the average of the scores is calculated if the difference between the two observers is of up to three points; if the difference is greater, they must review the behaviour and come to an agreement. The final score for each item is correlated with the scale criterion, to obtain the index of sensitivity for the attachment figure assessed (Posada et al., 2007). In literature review, the researcher found two studies that provide empirical support for the reliability and validity of MBPQS and of its four dimensions (Posada et al., 2007; Richmond, Posada, \& Jacobs, 2001). Concerning inter-observer reliability, recent transcultural studies placed it in a range between .81 (Peru) and .86 (United States) (Posada et al., 2016). As regards internal consistency reliability, the same transcultural studies report Cronbach's alpha between .93 (CHI) and .67 (LS) for the entire sample (Posada et al., 2016).

In the present study, the researcher recorded the behaviours of the 16 caregivers during their normal routine interaction with their children, in the natural environment of both of them (their home), within the space of an hour. Afterwards, two independent observers previously trained in the use of the MBPQS scale, assessed the behaviours. 
The average inter-observer reliability, calculated by using the intra-class correlation coefficient, was $.86(S D=0.07$, Min $=.73$, Max =.95). As far as the internal consistency reliability for the four MBPQS dimensions of sensitivity is concerned, high coefficients were found, which were similar to those reported by Posada et al. (2016): $\alpha=.96$ for CHI, $\alpha=.95$ for SBS, $\alpha=.71$ for SUP, and $\alpha=.81$ for LS.

4.2.2 Attachment Security. The attachment behaviour of the children who participated was assessed with the scale Attachment Behaviour QSet, Versión 3.0 (AQS) (Waters, 1995). Just like the previous scale, AQS consists of 90 statements that assess, in this case, behaviours related with attachment security; 50 of the statements refer to four dimensions: Smooth interactions with caregiver (SIM), Physical contact with caregiver (PCM), Interactions with other adults (IOA), and Proximity to caregiver (PM).

As was the case with the previous scale, two assessors observe independently the interactional behaviour of the child with her or his caregiver in their natural environment and assess the adult by applying the items in the AQS scale that are not easily observable (i.e., Item 3: "When he is upset or injured, child will accept comforting from adults other than caregiver."). Then, the assessors use the Q-sort methodology previously described, to evaluate the behaviour that was observed. The index of security is obtained by correlating the final scores corresponding to each item with the scale criterion (Waters, 1995).

In the present study, the AQS and the MBPQS scales were applied simultaneously. In the case of AQS, the researcher recorded the behaviour of the 16 children during their routine interaction with their caregivers, in an environment that is natural for both of them (their home), within the space of an hour. Afterwards, two previously trained independent observers assessed the behaviour of the children. The average inter-observer reliability found was $.87(S D=0.06, M i n=.76, \operatorname{Max}=.98)$; it was obtained by using the intra-class correlation coefficient. Internal consistency reliability for the four AQS dimensions of security, which was calculated using Cronbach's alpha, was $\alpha=.82$ for SIM,$\alpha=.696$ for PCM, $\alpha=.760$ for PM, y $\alpha=.847$ for IOA.

\subsection{Procedure}

The researcher visited each caregiver-child dyad at home on four occasions. During the first visit, the caregivers were informed about the goals, procedures, and their role in the study; doubts were dispelled and the informed consent was signed, i.e. the document through which they confirmed their will to participate, authorized the participation of their children and accepted the use of the data for research purposes. During the second visit, the initial interview was applied to gather sociodemographic information and obtain data concerning the development of the child. During the third visit, the researcher observed and recorded the routine dyadic interaction, in the natural environment, which lasted for approximately an hour. After which, he (the researcher) applied the interview questions corresponding to some of the items of the MBPQS and AQS that are not easily observable to the caregivers. During the last visit, the researcher gave recommendations that were aimed at strengthening the attachment bond with their children, in a conversational setting.

The footage of each of the filmed dyadic relation of the 16 participants was observed by four independent observers who had been previously trained in the use of the instruments; two of them assessed caregiver behaviour by using the MBPQS scale, and the other two assessed the behaviour of the child by using the AQS scale; the researcher used in all cases Q-sort methodology.

For data analysis, the researcher used descriptive statistics (mean, standard deviation, minimum and maximum scores), parametric statistics, basically, Pearson's correlation, and inferential statistics, fundamentally linear regression. These procedures allowed to analyze the characteristics of caregiver sensitivity and of attachment security of the children, as well as the link between sensitivity and security.

\section{Results}

Regarding the sensitivity of the 16 caregivers, this study found an average index of .43 (SD=0.44, Min=-.63, $M a x=.77, C I 95 \%=[.20, .67])$ corresponding the average scores of the participants and the sensitivity criterion of the MBPQS scale, an index which is situated within the range of the results found in other countries (e.g., Posada et al., 2016). Concerning the consistency of the caregiver's behaviour, it was found that high and very high correlations between sensitivity and its four dimensions, and among the dimensions themselves, as it can be observed in Table 1; besides, these correlations are statistically significant at a level of $p<.01$; the lowest link registered was between Limit Setting and Supervision and monitoring $(r=.53)$. 
Table 1: Correlation between caregiver sensitivity and its dimensions

\begin{tabular}{lccccc}
\hline & Sensitivity & CHI & SBS & SUP & LS \\
\hline Sensitivity & - & & & & \\
CHI & $.98^{* *}$ & - & & & \\
SBS & $.97^{* *}$ & $.96^{* *}$ & - & & \\
SUP & $.90^{* *}$ & $.90^{* *}$ & $.88^{* *}$ & - & \\
LS & $.80^{* *}$ & $.75^{* *}$ & $.76^{* *}$ & $.53^{* *}$ & - \\
\hline
\end{tabular}

Note: $\mathrm{CHI}=$ Contribution to harmonious interactions; SBS $=$ Secure base support; SUP $=$ Supervision and monitoring; LS = Limit Setting.

$* p<.05 ; * * p .01$

The analysis of sensitivity in relation to the sociodemographic data evidenced a statistically significant moderate positive correlation between sensitive caregiving and caregiver's age $(r=.526, C I 95 \%=[.04, .81]$, $p=.036$ ), a finding that is consistent with previous reports (Posada et al., 2016; Santelices et al., 2015); with respect to the link between sensitive caregiving and educational level of the caregiver, a positive moderate correlation was found, but it was not statistically significant $(r=.423, C I 95 \%=[-.09, .76], p=.102)$. Regarding the average scores obtained through the application of the MBPQS, data found discrepancies with the scale criterion that were higher than +-3 points in 6 of the 90 items, as it can be seen in Table 2 .

As it can be observed, two of the six items, which belong to the dimension Secure Base Support, received a score that was higher than the one registered in the scale, while the other three items (one of Secure Base Support and two of Supervision and monitoring), received a lower score. The analysis of the statement of those items allows us to infer that in the group of caregivers who participated there is, overall, a disposition to carry out activities based on what calls the attention of the child that was greater than what is considered to be the norm, while on the other hand, they show, overall, a tendency to sooth the child and prevent conflictive situations that is lower than the one described in the criteria.

Concerning the attachment security of the children, data revealed an average score of $.42(S D=0.17$, Min $=.02$, Max $=.71, C I 95 \%=[.33, .51])$, which is slightly higher than the one found in other countries (Posada et al., 2016). With regards to attachment security consistency (Table 3), data showed that for the children who participated in the study, security evinced a highly significant level of association with warmth in interactions with caregiver $(p<.01)$, a moderate significant level of association with the enjoyment of physical contact with her $(p<.05)$, and a moderate level of association with search for her proximity. It was also found that attachment security is independent from the kind of interaction that the child establishes with other adults, and that there is an association that is between low and null of the dimensions of attachment security among each other.

On the other hand, the correlations found between attachment security and some sociodemographic data such as child age $(r=.167, C I 95 \%=[-.353, .582], p=.537)$, and between attachment security and gender $(r=.138, C I$ $95 \%=[-.395, .588], p=.609)$ were low and not statistically significant. In reference to the Mean scores for the AQS scale (Table 4), data found discrepancies with the criterion that were higher than +-3 point in 11 of the 90 items.

Table 2: Discrepancies higher than +-3 points in $\operatorname{MBPQS}(N=16)$

\begin{tabular}{cclccc}
\hline $\begin{array}{c}\text { Item } \\
\mathbf{N}^{\circ}\end{array}$ & Dim & \multicolumn{1}{c}{ Statement } & $\begin{array}{c}\text { Avg. } \\
\text { Score }\end{array}$ & $\begin{array}{c}\text { Criterion } \\
\text { Score }\end{array}$ & Discr \\
\hline $\mathbf{5 7}$ & SBS & $\begin{array}{l}\text { When child is upset or sad, mom ignores him/her or is not very } \\
\text { skilled at comforting and re- orienting him/ her to play. }\end{array}$ & 5.06 & 1 & -4.06 \\
$\mathbf{3 6}$ & SBS & $\begin{array}{l}\text { Caregiver carries out activities based on what calls the attention } \\
\text { of child. }\end{array}$ & 6.75 & 3 & -3.75 \\
$\mathbf{4 0}$ & SUP & $\begin{array}{l}\text { Is two steps ahead of child, anticipates conflictive situations } \\
\text { and does something to prevent escalation }\end{array}$ & 5.03 & 8.5 & 3.47 \\
$\mathbf{5 5}$ & SBS & $\begin{array}{l}\text { When there is an accident, she immediately goes to child to } \\
\text { check on what happened. }\end{array}$ & 5.22 & 8.75 & 3.53 \\
$\mathbf{7 1}$ & SUP & $\begin{array}{l}\text { Follows or moves to a better location to supervise/ monitor as } \\
\text { child moves from place to place. }\end{array}$ & 4.69 & 8.25 & 3.56 \\
$\mathbf{6 2}$ & -- & $\begin{array}{l}\text { If upset or crying due to an accident, she picks him up until he } \\
\text { is soothed and ready to be put down. }\end{array}$ & 4.91 & 8.75 & 3.84 \\
\hline
\end{tabular}

Note: Dim $=$ Dimension to which the item belongs; Avg. Score = Average score for the 16 participant caregivers; Criterion Score = Scale criterion score; Discr = Discrepancy between Average Score and Criterion; SBS = Secure Base Support Dimension; SUP $=$ Supervision and Monitoring Dimension

The dashes -- in the Dim column indicate that the item does not correspond to any of the dimensions. 
Table 3: Correlation between attachment security and its dimensions

\begin{tabular}{lccccc}
\hline & Sensitivity & SIM & PCM & PM & IOA \\
\hline Sensitivity & - & & & & \\
SIM & $.76^{* *}$ & - & & & \\
PCM & $.59^{*}$ & .22 & - & & \\
PM & .49 & .02 & .38 & - & \\
IOA & .17 & -.15 & .08 & .07 & - \\
\hline
\end{tabular}

Note: SIM = Smooth Interactions with caregiver (warmth); PCM = Physical Contact with caregiver (enjoyment); $\mathrm{PM}=$ Proximity to caregiver (seeking); IOA = Interaction with other adults.

$* p<.05 ; * * p .01$

Table 4: Discrepancies higher than +-3 points in AQS $(N=16)$

\begin{tabular}{|c|c|c|c|c|c|}
\hline $\begin{array}{c}\text { Item } \\
N^{\circ}\end{array}$ & Dim & Statement & $\begin{array}{l}\text { Avg. } \\
\text { Score }\end{array}$ & $\begin{array}{l}\text { Criterion } \\
\text { Score }\end{array}$ & Discr \\
\hline 69 & PM & Rarely asks caregiver for help. & 2.3 & 6.63 & -4.33 \\
\hline 59 & PM & $\begin{array}{l}\text { When finishing an activity or play, generally finds something } \\
\text { else without turning to caregiver between activities }\end{array}$ & 3.8 & 7.56 & -3.76 \\
\hline 7 & IOA & Child laughs and smiles easily with different persons. & 4.3 & 7.5 & -3.2 \\
\hline 37 & -- & $\begin{array}{l}\text { Child is very active. Always moving around. Prefers active to } \\
\text { calm play. }\end{array}$ & 4.8 & 7.9 & -3.1 \\
\hline 68 & -- & On average, child is a more active person than caregiver. & 5 & 8.03 & -3.03 \\
\hline 53 & PCM & $\begin{array}{l}\text { When caregiver picks him/her up, child puts his/her arms around } \\
\text { her or on her shoulders. }\end{array}$ & 8.5 & 5.22 & 3.28 \\
\hline 11 & PM & $\begin{array}{l}\text { Frequently hugs or seeks contact with caregiver without her } \\
\text { asking or inviting him/her to do so. }\end{array}$ & 7.5 & 3.97 & 3.53 \\
\hline 71 & PCM & $\begin{array}{l}\text { If caregiver picks him/her up when scared or upset, child stops } \\
\text { crying and recovers quickly. }\end{array}$ & 8.8 & 4.97 & 3.83 \\
\hline 83 & PM & $\begin{array}{l}\text { When the child is bored s/he goes to caregiver looking for } \\
\text { something to do. }\end{array}$ & 6.5 & 2.66 & 3.84 \\
\hline 21 & PM & $\begin{array}{l}\text { When child plays at home, s/he keeps an eye on caregiver's } \\
\text { location. } \mathrm{S} / \text { he calls her from time to time, pays attention when } \\
\text { she changes site or activity. }\end{array}$ & 8.8 & 4.03 & 4.77 \\
\hline 90 & PM & $\begin{array}{l}\text { If caregiver goes very far, child follows her and continues to play } \\
\text { in the new site where she is. }\end{array}$ & 8.3 & 3.53 & 4.77 \\
\hline
\end{tabular}

Note $:$ Dim $=$ Dimension to which the item belongs; Avg. Score = Average score for the 16 participant children; Criterion Score $=$ Scale criterion score; Discr $=$ Discrepancy between Average Score and Criterion Score; PM = Proximity to caregiver (seeking) dimension; IOA = Interaction with other adults dimension; PCM $=$ Physical contact with caregiver (enjoyment) dimension.

The dashes -- in the Dim. column indicate that the item does not correspond to any of the dimensions.

Five of these 11 items (two corresponding to the dimension search for Proximity to caregiver, one to the dimension Interaction with other adults, and two that do not correspond to any of the dimensions) received a score that was lower than the scale criterion, while the remaining six items (two corresponding to the enjoyment of Physical contact with caregiver, and two corresponding to the search for Proximity with caregiver) received a higher score. The analysis of these items allows to infer that the group of children who participated appeared as shier, more dependent on their caregiver, and with higher levels of search for proximity and contact than what is registered as the norm in the scale, which could be related to cultural factors.

Regarding the central objective of this study, the researcher analyzed the predictive role of caregiver's sensitivity in relation to the security of the children, taking also into account the sociodemographic variables caregiver age and caregiver education, and the age and gender of the children. When all the variables were introduced simultaneously for the calculation of multiple linear regression, only sensitivity remained at a significant level as a predictor in the model $(F(1,14)=12.73, p=.003)$, while the sociodemographic variables were excluded. The relation that was found between sensitivity and security $(r=.690, r 2=.439, p=.003)$ indicates that they are directly, positively and significantly correlated, a correlation which is higher than that reported by other studies populations (e.g., Posada et al., 2016), and also that $44 \%$ of the variability in the attachment security of the children can be accounted for by the sensitivity of their caregivers.

In so far as the correlation between sensitivity and the four dimensions of attachment security is concerned, data found that the behaviour of the caregiver was significantly associated with the child's warmth during his/her 
interactions with her $(r=.59, p=.02)$, and with the search for proximity ( $r=49, p=.05)$; nevertheless, the analysed data did not find significant or marginally significant relations with the enjoyment that the child experiences through physical contact with his/her caregiver $(r=36, p=.17)$, neither with the interactions that a child establishes with other adults $(r=-.29, p=.29)$. On the other hand, it found that children's attachment security is significantly correlated with three of the four dimensions of caregiver's sensitivity: contribution to harmonious interactions $(r=.68, p=.004)$, secure base support $(r=.63, p=.01)$, and supervision and monitoring $(r=.57, p=.02)$. Data collated found that children's attachment security is marginally associated with limit setting by their caregivers $(r=.46$, $p=.08)$.

\section{Discussion}

The present study was based on the sensitivity hypothesis of attachment theory, which relates sensitive caregiving with attachment security (van IJzendoorn \& Sagi-Schwartz, 2008). With the aim of generating contextual knowledge and of making available referential data that can serve as a base for future studies, the researcher worked with 16 caregivers and their typically developing preschool children, residents of Kpandai District; this is a context in which there is no research available on this subject. The goal was to analyze the relationship between sensitivity and security in the studied population.

Regarding the sociodemographic characteristics of the participants, the study found two interesting facts. On the one hand, found that for $100 \%$ of the cases the children's principal caregivers were caregivers, and that the latter consider the father as an aid in childrearing, and that they perceive themselves as being the main responsible caregiver. Nonetheless, the majority of them have an academic educational background that allows them to do well in the work sphere (in this research, $81 \%$ have higher education: $62 \%$ at undergraduate level and $19 \%$ at graduate level). On the other hand, it was observed that $50 \%$ of the children were only children, which reflects a tendency in the make-up of Ghanaian families that live in the cities.

Concerning caregiver's sensitivity, the researcher found among the participants an average rate of .43, which is similar to what other studies with similar population reported (e.g., Posada et al., 2016), particularly, the findings corresponding to Mexico (.46) and Colombia (.48) (Posada et al., 2016). The study also found that caregiver's sensitivity is related to their age; this allows to conclude that maturity is positively associated with sensitive behaviour; this finding has been previously reported by different research studies (e.g., Bornstein, Hendricks, Haynes, \& Painter, 2007; Posada et al., 2016; Santelices et al., 2015). Additionally, the study found that the different dimensions of the participants' sensitive behaviour are linked to one another; this allows to infer that they have developed their sensitivity with the same intensity in the different domains.

Moreover, the study can observe, in general terms, that caregivers who contribute to the establishment of harmonious interactions, who support their children in the establishment of a secure base, who supervise and monitor them, and set limits in a sensitive way, have children who have developed a secure attachment bond with them. In spite of that, attention is drawn to the high dispersion of some scores, which in some cases reach negative values; although in a strict sense, that would be indicative of low sensitivity, it is important to consider that the rearing practices vary from one context to the other (e.g., Keller, 2013; Quinn \& Mageo, 2013), and that intracultural variations are often even higher than intercultural ones (Mesman et al., 2016), something that can be more evident in multicultural countries (Villamarín, 2017). In fact, the scores of the items shown in Table 2 indicate, on the one hand, that when extreme scores are averaged, they fall within the mean values, but, on the other, they also show a general tendency of the caregivers to situate themselves in a middle ground between protecting their child and letting him/her face the situations with his/her own resources, which can be different from what is registered as the norm, but not, on account of that, less sensitive.

Regarding attachment security, the children participating in this study, as a group, reached scores (.42) that were superior to those of other groups of children, under comparable sociodemographic conditions (Nóblega, 2012; Posada et al., 2013; Posada et al., 2016). In addition, they all obtained positive scores, which indicates that, in general terms, they have developed an adequate level of security in their attachment relationships. Still, in contrast with caregiver behaviour, the children that were studied do not show a high consistency in their behaviours; although the study found a high association with warmth in their interactions with caregiver, the relationship between attachment security, enjoyment of physical contact with caregiver and search for proximity with her is just moderate.

Additionally, the results also confirmed a fact that had been previously reported in studies of the Peruvian population related to the relative independence between the nature of the interaction that the child establishes with other adults and his/her overall security level (Nóblega, 2012). In the face of this result, the cultural aspects have been considered as a possible explanation, in the sense that in this contexts great importance is given to respect and to the child's compliance with certain behavioural norms in relation to other persons (Nóblega, 2012). In fact, the high scores of the child participants in several items related to the search of proximity to caregiver can be considered as a confirmation of this claim in the sense that, in the presence of unknown persons, they seek shelter in their caregivers. 
In relation to the main goal, the study found that sensitivity was a variable that was predictive, at a significant level, of attachment security, and the relation between them .69, which is higher to the one found in the metaanalyses carried out internationally (e.g. Atkinson et al., 2000), and in other studies which report a range between .30 in Mexico and .43 in Peru (Posada et al., 2016).

\section{Conclusions}

To sum up, the results of the present study allow to conclude that the caregivers in Kpandai District who participated show a level of sensitivity towards their preschool children's needs similar to the one found in other studies. The researcher also found an association between caregiver age and sensitive behaviour and a high correlation among the four dimensions of sensitivity. An interesting fact that was observed in the interaction is that the caregivers, in general terms, tend to let the children face situations with their own resources, which seems to relate to a child-rearing practice in Ghana.

Concerning children's attachment security, the study found a level that was slightly higher than what other studies reported; in addition, the study found a high correlation between security and warmth in interactions with caregiver; a moderate correlation with the enjoyment of physical contact with her, and with proximity seeking; a relative independence between security and interaction with other adults, which is probably on account of the respect and the distance that characterizes the relation of children with older persons.

As it was the case with other investigations, this research found that sensitivity was a predictor of attachment security; besides, it found associations between sensitivity of the caregiver and warmth and proximity-seeking on the part of the child, as well as between the child's security and the caregiver's contribution to harmonious interactions. Since Kpandai is a diverse and multicultural District, these results can serve as a base for further investigations, in which the paternal figure be included, as well as children from other cultural contexts and with different developmental conditions, so as to achieve an increased knowledge on this subject.

It is worth considering as limitations to this study, the low number of participants and of visits carried out for each dyad. Furthermore, it is necessary to emphasize that some methodological aspects could have favoured the results obtained, such as the ages of the children, the nature of the methods used for data collection, as well as the temporal simultaneity of the measurement of caregiver and child behaviour; these factors that have been reported in the literature as being influential in relation to the increase of the values of the correlations (e.g., Atkinson et al., 2000; Nóblega, 2012).

\section{References}

Ainsworth, M. D. (1973). Infancy in Uganda: Infant care and the growth of love. Baltimore: Johns Hopkins University.

Atkinson, L., Niccols, A., Paglia, A., Coolbear, J., Parker, K., Poulton, K., \& Sitarenios, G. (2000). A Metaanalysis of time between caregiver sensitivity and attachment assesments: Implications for internal working models in infancy/toddlerhood. Journal of Social and Personal Relationships, 17, 791-810. doi: $10.1177 / 0265407500176005$

Bergin, C., \& Bergin, D. (2009). Attachment in the Classroom. Educational Psychology Review, 21, $141-170$. doi:10.1007/s10648-009-9104-0

Bornstein, M. H., Hendricks, C., Haynes, O. M., \& Painter, K. M. (2007). Caregiver sensitivity and child responsiveness: Associations with social context, caregiver characteristics, and chid characteristics in a multivariate analysis. Infancy, 12(2), 189-223. doi:10.111/j.1532-7078.2007.tb00240.x

Bowlby, J. (1969). El Apego y la Pérdida: El Apego (Vol. 1). Barcelona: Ediciones Paidós Ibérica.

Dozier, M., Stovall, K. C., Albus, K. E., \& Bates, B. (2001). Attachment for infants in foster care: the role of caregiver state of mind. Child Development, 72(5), 1467-1477. doi:10.1111/1467-8624.00360

Dunst, C. J., \& Kassow, D. Z. (2004). Caregiver Sensitivity , Contingent Social Responsiveness, and Secure Infant Attachment. JEIBI, 5(1), 40-56. Retrieved from http://psycnet.apa.org/journals/eib/5/1/40.html

Gerber, E. B., Whitebook, M., \& Weinstein, R. S. (2007). At the heart of child care: Predictors of teacher sensitivity in center-based child care. Early Childhood Research Quarterly, 22, 327-346. doi:10.1016/j.ecresq.2006.12.003

Hamre, B. K. (2014). Teachers' Daily Interactions With Children: An Essential Ingredient in Effective Early Childhood Programs. Child Development Perspectives, 8(4), 223-230. doi:10.1111/cdep.12090

Hamre, B. K., \& Pianta, R. C. (2011). Early teacher-child relationships and the trajectory of children's school outcomes through eighth grade. Child Development, 72(2), 625-638. doi:10.1111/1467-8624.00301

Hopkins, J., Gouze, K. R., \& Lavigne, J. V. (2013). Direct and indirect effects of contextual factors, caregiver depression, and parenting on attachment security in preschoolers. Attachment \& Human Development, 15(2), 155-73. doi:10.1080/14616734.2013.750702

Keller, H. (2013). Attachment and Culture. Journal of Cross-Cultural Psychology, 44(2), 175-194. doi:10.1177/0022022112472253 
Mashburn, A. J., Pianta, R. C., Hamre, B. K., Downer, J. T., Barbarin, O. a, Bryant, D., ... Early, D. M. (2008). Measures of Classroom Quality in Prekindergarten and Children's Development of Academic , Language , and Social Skills. Child Development, 79(3), 732-749.

Mesman, J., van IJzendoorn, M. H., \& Sagi-Schwartz, A. (2016). Cross-Cultural Patterns of Attachment: Universal and Contextual Dimensions. In J. Cassidy, \& P. R. Shaver (Eds.), Handbook of Attachment: Theory, Research and Clinical Applications (3 ed., pp. 852- 877). New York: The Guilford Press.

Nóblega, M. (2012). Conducta de base segura y sensitividad en niños y madres del Distrito Los Olivos. Tesis para optar el Grado de Doctora en Psicología. Lima, Perú: Pontificia Universidad Católica del Perú.

Oliveira, P. S., Fearon, R. M. P., Belsky, J., Fachada, I., \& Soares, I. (2014). Quality of institutional care and early childhood development. International Journal of Behavioral Development, 39(2), 161-170. doi: $10.1177 / 0165025414552302$

Paro, K. M. La, Hamre, B. K., Locasale-Crouch, J., Pianta, R. C., Bryant, D., Early, D., ... Burchinal, M. (2009). Quality in Kindergarten Classrooms: Observational Evidence for the Need to Increase Children's Learning Opportunities in Early Education Classrooms. Early Education \& Development (Vol. 20). doi:10.1080/10409280802541965

Posada, G., Kaloustian, G., Richmond, M. K., \& Moreno, A. (2007). Caregiver secure base support and preschoolers' secure base behaviour in natural environments. Attachment \& Human Development, 9(4), 393 - 411. doi:10.1080/14616730701712316

Posada, G., Trudel, M., Plata, S. J., Peña, P. P., Pérez, J., Tereno, S., . . Keng-Ling, L. (2013). Is the Secure Base Phenomenon Evident Here, There, and Anywhere? A Cross-Cultural Study of Child Behaviour and Experts' Definitions. Child Development, 84(6), 1896- 1905. doi:10.1111/cdev.12084

Posada, G., Trumbell, J., Nóblega, M., Plata, S., Peña, P., Carbonell, O., \& Lu, T. (2016). Caregiver Sensitivity and Child Secure Base Use in Early Childhood: Studies in Different Cultural Contexts. Child Development, 87(1), 297-311. doi:10.1111/cdev.12454

Quinn, N., \& Mageo, J. M. (2013). Attachment Reconsidered: Cultural Perspectives on a Western Theory. New York: NY Palgrave Macmillan.

Richmond, M., Posada, G., \& Jacobs, A. (2001). Caregiver behaviour and attachment security in 3 year-olds: A naturalistic study. Poster presented at the meeting of the Society for Research in Child Development. Minneapolis, MN.

Ritchie, S., \& Howes, C. (2003). Program practices, caregiver stability, and child-caregiver relationships. Journal of Applied Developmental Psychology, 24, 497-516. doi:10.1016/S0193-3973(03)00028-5

Santelices, M. P., Farkas, C., Montoya, M. F., Galleguillos, F., Carvacho, C., Fernández, A., ... Himmel, É. (2015). Factores predictivos de sensibilidad materna en infancia temprana. Psicoperspectivas, 14(1), $66-76$. doi:10.5027/PSICOPERSPECTIVAS-VOL14- ISSUE-FULLTEXT-441

van Ijzendoorn, M. H., \& Sagi-Schwartz, A. (2008). Cross-cultural patterns of attachment: Universal and contextual dimensions. In J. Cassidy, \& P. R. Shaver (Eds.), Handbook of Attachment: Theory, Research and Clinical Applications (2 ed., pp. 880-905). New York. US: The Guilford Press.

Villamarín, G. (2017). Consideraciones culturales sobre la práctica de la Psicología: el caso de la Teoría del Apego. Programa de Maestría en Estudios de la Cultura. Quito: Universidad Andina Simón Bolívar, sede Ecuador.

Waters, E. (1995). Appendix A: The Attachment Q Set. (E. Waters, B. Vaughn, G. Posada, \& K. Kondo-Ikemura, Eds.) Monographs of the Society for Research in Child Development, 60(2-3), 234 - 246. doi:10.2307/1166181 